\title{
Resistencia antimicrobiana y genotipificación de cepas de Salmonella Typhimurium aisladas de cuyes (Cavia porcellus) provenientes de granjas de producción intensiva de la ciudad de Lima, Perú
}

\author{
ANTIMICROBIAL RESISTANCE AND GENOTYPING OF $\boldsymbol{S}_{\text {ALMONELLA }}$ TYPHIMURIUM STRAINS \\ ISOLATED FROM GUINEA PIGS (Cavia porcellus) FROM INTENSIVE PRODUCTION \\ Farms of The CITy OF Lima, Peru \\ Guillermo Salvatierra R. ${ }^{1}$, Rocío Rimac B. ${ }^{1}$, Ana Chero O. ${ }^{1}$, Iván Reyna W. ${ }^{1}$, \\ Raúl Rosadio A. ${ }^{1}$, Lenin Maturrano H. ${ }^{2,3}$
}

\section{Resumen}

El objetivo del estudio fue caracterizar 20 cepas de Salmonella enterica a nivel molecular y de resistencia antimicrobiana. De estas, 15 fueron obtenidas de cuyes infectados y cinco de cuyes clínicamente sanos, procedentes de dos centros de producción intensiva ubicados en Lima, Perú. Mediante una técnica de PCR múltiple se detectaron los genes invA, prot $6 \mathrm{E}$ y fliC, correspondientes al género Salmonella y serovares Enteritidis y Typhimurium, respectivamente. Se detectó la variabilidad genética mediante la técnica BOX-PCR utilizando el primer BOXA1R. La resistencia fue evaluada utilizando la técnica de Kirby Bauer en base a eritromicina, nitrofurantoína, estreptomicina, penicilina, enrofloxacina, fosfomicina, amoxicilina con ácido clavulánico, sulfatrimetoprim y ciprofloxacina. Se evidenció la serovariedad Typhimurium en el 100\% de los aislados. La evaluación de los perfiles electroforéticos obtenidos por la técnica de BOX-PCR demostró alta homogeneidad, con patrones de bandas de ADN similares. Se detectaron cepas resistentes a eritromicina $60 \%(12 / 20)$, nitrofurantoína 40\% (8/20), estreptomicina 30\% (6/ $20)$, penicilina $25 \%(5 / 20)$, y enrofloxacina $10 \%(2 / 20)$. La detección de cepas resistentes puede ocasionar problemas en el tratamiento de salmonelosis en cuyes y la presencia de un solo grupo genético sugiere una dispersión clonal.

Palabras clave: salmonelosis; cuyes; Typhimurium; BOX-PCR; resistencia antimicrobiana

\footnotetext{
${ }^{1}$ Laboratorio de Microbiología y Parasitología Veterinaria, ${ }^{2}$ Laboratorio de Zootecnia y Producción Agropecuaria, Facultad de Medicina Veterinaria, Universidad Nacional Mayor de San Marcos, Lima, Perú

${ }^{3}$ E-mail: amaturranoh@unmsm.edu.pe
}

Fuente financiera: Proyecto ${ }^{\circ} 362$ PNICP-PIAP 2014 «Desarrollo de una vacuna para el control y prevención de la salmonelosis en la producción cuyes»

Recibido: 12 de mayo de 2017

Aceptado para publicación: 22 de septiembre de 2017 
The aim of this study was to characterize 20 strains of Salmonella enterica at molecular level and antimicrobial resistance. Of these, 15 strains were obtained from infected guinea pigs and five from clinically healthy guinea pigs from two intensive production centers located in Lima, Peru. The invA, prot $6 \mathrm{E}$ and $f l i \mathrm{C}$ genes corresponding to the genus Salmonella and serovars Enteritidis and Typhimurium, respectively, were detected by a multiple PCR technique. Genetic variability was detected using the BOX-PCR technique using the first BOXA1R. Resistance was evaluated using the Kirby Bauer technique based on erythromycin, nitrofurantoin, streptomycin, penicillin, enrofloxacin, fosfomycin, amoxicillin with clavulanic acid, sulfatrimetoprim and ciprofloxacin. Serotype Typhimurium was determined in $100 \%$ of the isolates. The evaluation of the electrophoretic profiles obtained by the BOX-PCR technique demonstrated high homogeneity, with similar DNA bands patterns. Strains resistant to erythromycin $60 \%(12 / 20)$, nitrofurantoin $40 \%(8 / 20)$, streptomycin 30\% (6/20), penicillin 25\% (5/20), and enrofloxacin 10\% (2/20) were detected. The detection of resistant strains may cause problems in the treatment of salmonellosis in guinea pigs and the presence of only a genetic group suggests a clonal dispersion.

Key words: salmonellosis; guinea pigs; Typhimurium; BOX-PCR; antimicrobial resistance

\section{INTRODUCCIÓN}

La salmonelosis es la enfermedad más grave que afecta a los cuyes, causando alta mortalidad y morbilidad, y puede ir acompañada de casos de abortos (Chauca, 1997). Existen actualmente más de 2610 serovariedades de Salmonella reconocidas en el mundo, y casi todas son capaces de causar enfermedad en humanos y animales (Guibourdenche et al., 2010). Los principales serovares aislados de cuyes son Typhimurium y Enteritidis (Richardson, 2000), estando el primero presente en más del 95\% de los casos (Chauca, 1997). Asimismo, ambos serovares son los más frecuentes en casos de salmonelosis en el humano (Fardsanei et al., 2016).

La discriminación genética entre aislados de Salmonella es de gran utilidad como herramienta epidemiológica, proveyendo información para mejoras en programas de prevención y control (Sabat et al., 2013). Los métodos de tipificación basados en rep-PCR utilizan cebadores (primers) que hibridan se- cuencias intergénicas no codificantes dispersas en todo el genoma. Estas secuencias han sido utilizadas para la caracterización de Salmonella en la distinción de especies, cepas, serovares, etc. (Lupiski et al., 1992; Versalovic et al., 1994; Rampadarath et al., 2015). Una de las aplicaciones actuales para estas técnicas es la identificación de polimorfismos genéticos para determinar variabilidad y delinear relaciones epidemiológicas en la vigilancia y monitoreo de brotes (Lim et al., 2005; Tunung et al., 2007; LearnHan et al., 2008; Prasertsee et al., 2016).

El incremento de aislados de Salmonella resistentes a antimicrobianos es un serio problema de salud pública en todo el mundo. La detección de cepas resistentes a antimicrobianos usados de manera rutinaria plantea limitaciones graves en las posibilidades de tratamiento eficaz (Su et al., 2004). Las cepas de Salmonella resistentes no solo implican un riesgo para la salud animal, pues se ha demostrado la capacidad que tiene la bacteria de transmitirse a humanos por la cadena alimenticia, convirtiéndolo en un verdadero problema de salud pública (Threfall, 2002). 
El objetivo del estudio fue la caracterización molecular de 20 aislados de Salmonella enterica provenientes de cuyes, mediante una técnica de PCR Múltiple para la serotipificación molecular y la examinación de huellas genéticas y variabilidad usando una PCR de secuencias repetitivas BOX. Asimismo, determinar los perfiles de resistencia a antimicrobianos.

\section{Materiales y Métodos}

\section{Material Experimental}

Se analizaron 20 aislados de Salmonella enterica obtenidos de cuyes. Quince aislados fueron recuperados de muestras de hígado de cuyes diagnosticados con salmonelosis y los cinco restantes fueron recuperados a partir de muestras de hisopado rectal de cuyes clínicamente sanos de dos centros de producción intensiva ubicados en los distritos de Huaral y Manchay en Lima, Perú, respectivamente. Ambas granjas, presentan brotes focalizados de salmonelosis de manera continua, con un incremento en las estaciones de mayor temperatura. Todos los aislados fueron identificados según norma ISO 6579:2002.
El procesamiento de las muestras se realizó en el Laboratorio de Biología y Genética Molecular de la Facultad de Medicina Veterinaria de la Universidad Nacional Mayor de San Marcos, Lima, Perú, durante los meses de setiembre y octubre de 2016.

\section{Extracción de ADN Bacteriano}

Se realizó la extracción de ADN con el kit «GeneJET Genomic DNA Purification Kit» de ThermoFisher Scientific ${ }^{\mathrm{TM}}$ para bacterias Gram negativas, siguiendo los pasos de lisis nucleica, degradación de RNA, precipitación proteica, lavado con alcoholes y rehidratación del ADN (Thermo Fisher Scientific, 2014).

\section{Serovariedad Typhimurium}

Se realizó una PCR múltiple para la detección del gen $i n v \mathrm{~A}$, que permite determinar que el DNA extraído corresponde a un microorganismo perteneciente al género Salmonella, y los genes fliC y prot6E que permiten determinar la serovariedad Typhimurium y Enteritidis, respectivamente.

Las secuencias de oligonucleótidos están descritas en el Cuadro 1 (Jamshidi et al., 2010). Se trabajó con un volumen de reac-

Cuadro 1. Secuencia y tamaño $(\mathrm{pb})$ de cebadores (Forward-Reverse [F-R]) utilizados en la PCR múltiple

\begin{tabular}{cclc}
\hline Gen & Cebador & Secuencia cebador 5 ${ }^{\prime}-3$, & $\begin{array}{c}\text { Producto } \\
(\mathrm{pb})\end{array}$ \\
\hline \multirow{2}{*}{ invA } & S139-F & GTGAAATTATCGCCACGTTCGGGCAA & 284 \\
& S141-R & TCATCGCACCGTCAAAGGAACC & \\
\multirow{2}{*}{$f l i \mathrm{C}$} & Fli15-F & CGGTGTTGCCCAGGTTGGTAAT & 559 \\
& Tym-R & ACTCTTGCTGGCGGTGCGACTT & \\
\multirow{2}{*}{ prot6E } & Prot6e-5-F & ATATCGTCGTTGCTGCTTCC & 185 \\
& Prot6e-6-R & CATTGTTCCACCGTCACTTTG & \\
\hline
\end{tabular}


ción de $15 \mu$ l que contenía $2 \mu 1$ de ADN, 7.5 $\mu 1$ QIAGEN Master Mix Multiplex, los cebadores para detección de genes invA y prot $6 \mathrm{E}$ en concentración de $1 \mu \mathrm{M}$ y el cebador para detección del gen $f l i \mathrm{C}$ en concentración de $0.5 \mu \mathrm{M}$. Adicionalmente a los aislados, se utilizaron Salmonella Typhimurium ATCC 14028 y Salmonella Enteritidis ATCC 13076 como controles.

Las condiciones de los ciclos fueron $5 \mathrm{~min}$ a $95{ }^{\circ} \mathrm{C}$ para una desnaturalización inicial, 35 ciclos de $45 \mathrm{~s} \mathrm{a} 95^{\circ} \mathrm{C}$ para desnaturalización, $45 \mathrm{~s}$ a $58^{\circ} \mathrm{C}$ para hibridación, $45 \mathrm{~s}$ a $72^{\circ} \mathrm{C}$ para elongación y 7 min a $72{ }^{\circ} \mathrm{C}$ para una elongación final. Para la PCR se utilizó un termociclador Bio-Rad MyCycler. Los productos de PCR fueron analizados por electroforesis utilizando un gel de agarosa al $1.5 \%$, un marcador de peso molecular de 100 bp y TBE como buffer de corrida, a $100 \mathrm{~V}$ y $100 \mathrm{~mA}$ por $2 \mathrm{~h}$. El gel fue teñido con bromuro de etidio $(1 \mu \mathrm{g} / \mathrm{ml})$ y las bandas fueron observadas en un transiluminador UV Cleaver Scientific MUV-245/365 para su fotografiado.

\section{BOX-PCR}

Para detectar la diversidad genética entre las cepas se utilizó la técnica de BOXPCR, empleando el cebador BOXA1R descrito por Versalovic et al. (1991): 5'CTACGGCAAGGCGACGCTGACG-3'. Se trabajó con un volumen de reacción de $15 \mu 1$ que contenía $2 \mu \mathrm{l}$ de ADN, $7.5 \mu$ Q QIAGEN Master Mix Multiplex y el cebador BOXA1R en concentración de $2 \mu \mathrm{M}$. Se utilizaron, además, como controles a Salmonella Typhimurium ATCC 14028, Salmonella Enteritidis ATCC 13076, Escherichia coli y Pasteurella multocida, siendo los dos últimos obtenidos del cepario de este laboratorio.

Las condiciones de los ciclos fueron $5 \mathrm{~min}$ a $95^{\circ} \mathrm{C}$ para una desnaturalización inicial, 30 ciclos de $3 \mathrm{~s}$ a $94{ }^{\circ} \mathrm{C}$ para una primera desnaturalización, $30 \mathrm{~s} \mathrm{a} 92{ }^{\circ} \mathrm{C}$ para una segunda desnaturalización, 1 min a $50{ }^{\circ} \mathrm{C}$ para hibridación, 8 min a $65^{\circ} \mathrm{C}$ para elongación y 8 min a $65^{\circ} \mathrm{C}$ para una elongación final. Para la PCR se utilizó un termociclador Bio-Rad MyCycler.

Los productos de PCR fueron analizados por electroforesis utilizando un gel deagarosa al $1.5 \%$, un marcador de peso molecular de 100 bp y 1000 pb y TBE como buffer de corrida a $100 \mathrm{~V}$ y $100 \mathrm{~mA}$ por $3 \mathrm{~h}$. El gel fue teñido con bromuro de etidio $(1 \mu \mathrm{g} / \mathrm{ml})$ y las bandas se visualizaron en el transiluminador UV Cleaver Scientific MUV$245 / 365$ para su fotografiado.

\section{Análisis de Datos}

En la PCR múltiple se realizó la identificación de las bandas correspondientes a Salmonella spp que fueron de $284 \mathrm{pb}$ y a los serovares Typhimurium y Enteritidis de 559 y $185 \mathrm{pb}$, respectivamente. Para evaluar la diversidad de los aislados, se realizó el análisis de agrupamiento (clusters) para generar un dendrograma usando el programa bioinformático NTSYSpc 2.10, empleando el método UPGMA, basado en el coeficiente de similaridad de DICE. La matriz de distancias se construyó a partir de datos binarios (presencia/ausencia de bandas) obtenidos del análisis de BOX-PCR. Las distancias genéticas relativas encontradas fueron utilizadas para elaborar el dendrograma e ilustrar las relaciones genéticas calculadas a partir de los datos.

\section{Prueba de Sensibilidad Antimicrobiana}

Se utilizó la técnica de Kirby Bauer según los métodos recomendados para la prueba de sensibilidad e interpretación de halos de inhibición del CLSI (2009). Se utilizaron nueve antimicrobianos: eritromicina $(15 \mu \mathrm{g})$, nitrofurantoína $(300 \mu \mathrm{g})$, estreptomicina $(10 \mu \mathrm{g})$, enrofloxacina $(5 \mu \mathrm{g})$, penicilina (10 U), amoxicilina con ácido clavulánico $(30 \mu \mathrm{g})$, sulfatrimetoprim $(25 \mu \mathrm{g})$, ciprofloxacina $(5 \mu \mathrm{g})$ y fosfomicina $(200 \mu \mathrm{g})$. Los puntos de corte se basaron en los especifica- 


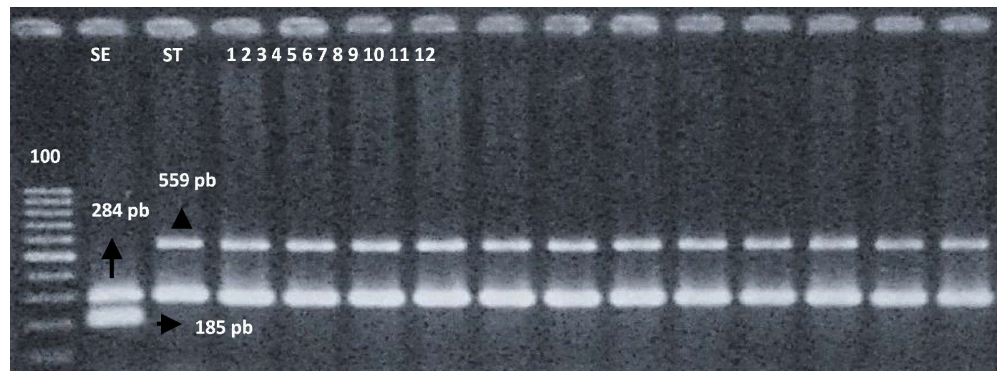

Figura 1. PCR múltiple utilizando tres cebadores. Los productos amplificados de $559 \mathrm{pb}$ del gen fli $\mathrm{C}$ específico para la serovariedad Typhimurium, de $284 \mathrm{pb}$ del gen invA específico para género Salmonella spp y de $185 \mathrm{pb}$ del gen prot6E específico para la serovariedad Enteritidis. $100=$ marcador de peso molecular de $100 \mathrm{pb} ; \mathrm{SE}=$ Salmonella Enteritidis; ST = Salmonella Typhimurium; 1-12 = aislados analizados

dos por CLSI (2009). Las cepas que presentaron resistencia a tres o más fármacos no relacionados se consideraron como resistentes a múltiples drogas (MDR).

\section{Resultados}

Todos los aislados amplificaron las secuencias invA de $284 \mathrm{pb}$ y fliC de $559 \mathrm{pb}$, correspondientes al género Salmonella y serovariedad Typhimurium, respectivamente. No hubo amplificación de la secuencia prot6E de $185 \mathrm{pb}$ correspondiente a la serovariedad Enteritidis (Figura 1). Todos los aislados (20/20) fueron identificados como Salmonella Typhimurium.

Los aislados de Salmonella Typhimurium fueron analizados mediante repPCR. Los patrones de las huellas genéticas generadas con el uso de primer BOX1AR mostraron alta homogeneidad entre los aislados. Cada aislado presentó un total de 10 bandas con un tamaño en rangos de $300 \mathrm{pb}$ a $2500 \mathrm{pb}$. El diseño de un dendrograma permitió detectar la presencia de un solo grupo genético, con $100 \%$ de similitud (Figura 2).
La evaluación de resistencia a antimicrobianos fue realizada mediante la técnica de Kirby Bauer. Se detectaron aislados resistentes principalmente a eritromicina $60 \%(12 /$ $20)$, seguido por nitrofurantoína $40 \%(8 / 20)$, estreptomicina $30 \%(6 / 20)$, penicilina $25 \%(5 /$ $20)$, y enrofloxacina $10 \%(2 / 20)$. No se detectó resistencia para amoxicilina con ácido clavulánico, sulfatrimetoprim, ciprofloxacina $\mathrm{y}$ fosfomicina (Cuadro 2).

El 25\% (5/20) presentó resistencia a tres o más antimicrobianos, considerándose como cepas MDR (multidrogo-resistente). Entre ellos, eritromicina-penicilina-nitrofurantoína (2), eritromicina-nitrofurantoína-estreptomicina (1), eritromicina-enrofloxacinanitrofurantoína-estreptomicina (1) y eritromicina-penicilina-nitrofurantoínaeritromicina (1).

\section{Discusión}

Todos los aislados fueron identificados como Salmonella Typhimurium mediante el uso de una PCR múltiple. Si bien existen estudios que han identificado la presencia de varias serovariedades de Salmonella en 


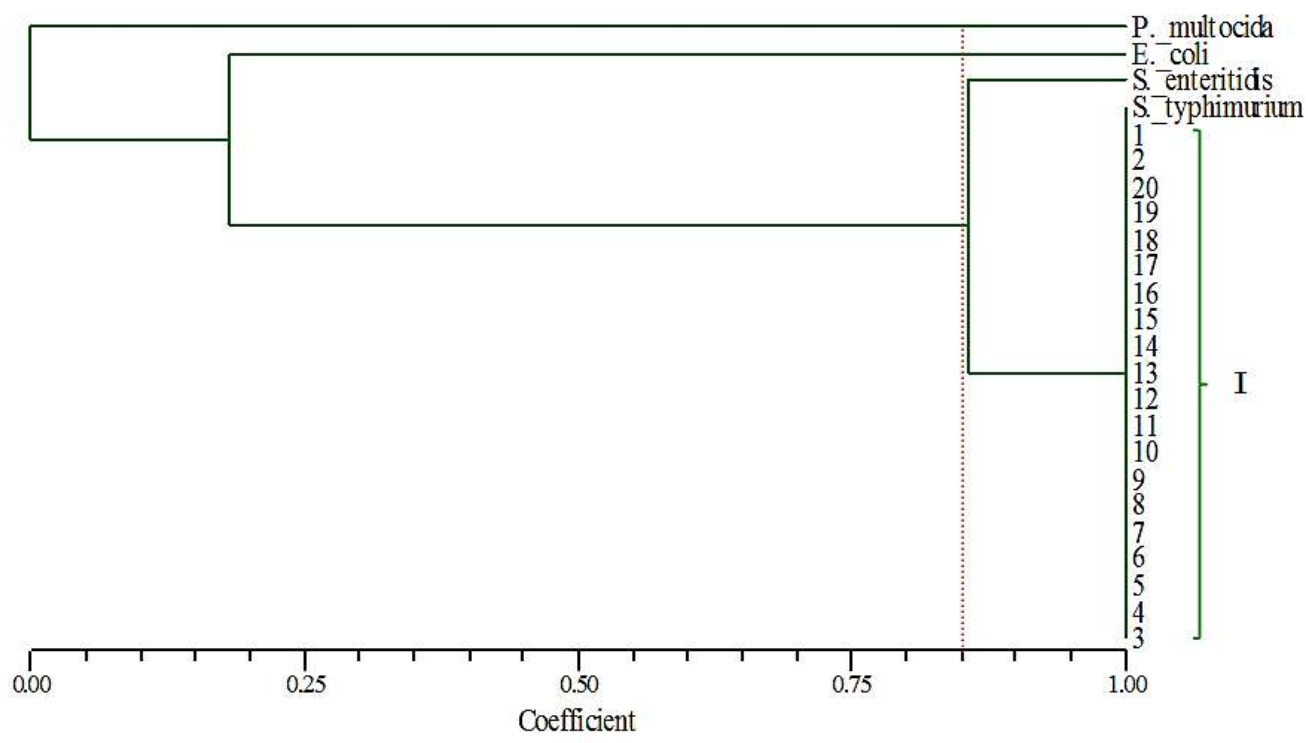

Figura 2. Dendrograma que muestra los resultados de BOX-PCR de 20 aislados de Salmonella Typhimurium, así como de aislados de Pasteurella multocida, Escherichia coli, Salmonella Enteritidis ATCC 13076 y Salmonella Typhimurium ATCC 14028. Se observa una similitud del $100 \%$ utilizando el coeficiente de DICE entre los aislados

cuyes, tales como Typhimurium, Enteritidis y Abortusequi entre otras, Salmonella Typhimurium es la serovariedad aislada con mayor frecuencia y está asociada a casos clínicos con altas tasas de mortalidad e inclusive con la ocurrencia de casos crónicos (Pivnick et al., 1966; Chauca, 1997; Richardson, 2000; Singh et al., 2005; Casart y Falconí, 2016).

Los aislados de Salmonella Typhimurium fueron genotipificados mediante el uso de una reacción en cadena de la polimerasa de elementos repetitivos (rep-PCR) conocida como BOX PCR. Esta técnica hibrida secuencias intergénicas no codificantes dispersas en el genoma, produciendo múltiples amplicones de distinto peso molecular, los cuales son caracterizados mediante una electroforesis y los patrones de bandas son comparados para determinar la relación genética entre los aislados (Lupiski et al., 1992; Versalovic et al., 1994; Rampadarath et al., 2015).
El uso de una BOX-PCR y el diseño de un dendrograma con base a la presencia o ausencia de bandas demostró una alta homogeneidad de todos los aislados de Salmonella Typhimurium del estudio. Existen estudios que han reportado el poder discriminatorio de los métodos de tipificación basados en secuencias repetitivas, que permiten identificar la serovariedad e inclusive subclasificar dentro de un mismo serovar (Botteldoorn et al., 2004; Prasertsee et al., 2016). Por ello, la detección de un solo grupo genético con una similitud total entre los aislados podría sugerir una dispersión clonal entre los centros de producción.

El mayor porcentaje de resistencia obtenido en la prueba de sensibilidad antimicrobiana fue para eritromicina. Los macrólidos no son el tratamiento de elección para la salmonelosis en cuyes porque puede resultar en toxicidad por alteración de la flora Gram positiva del intestino, permitiendo la proliferación de las bacterias Gram negati- 
Cuadro 2. Frecuencia y porcentajes obtenidos en la prueba de sensibilidad antimicrobiana de 20 aislados de Salmonella enterica obtenidos de cuyes

\begin{tabular}{lcccccc}
\hline \multirow{2}{*}{ Antimicrobianos } & \multicolumn{2}{c}{ Resistente } & \multicolumn{2}{c}{ Intermedio } & \multicolumn{2}{c}{ Sensible } \\
\cline { 2 - 7 } & $\mathrm{n}$ & $\%$ & $\mathrm{n}$ & $\%$ & $\mathrm{n}$ & $\%$ \\
\hline Eritromicina & 12 & 60 & 8 & 40 & 0 & 0 \\
Enrofloxacina & 2 & 10 & 9 & 45 & 9 & 45 \\
Amoxicilina con ácido clavulánico & 0 & 0 & 0 & 0 & 20 & 100 \\
Penicilina & 5 & 25 & 0 & 0 & 15 & 75 \\
Sulfatrimetoprim & 0 & 0 & 0 & 0 & 20 & 100 \\
Ciprofloxacina & 0 & 0 & 0 & 0 & 20 & 100 \\
Nitrofurantoína & 8 & 40 & 1 & 5 & 11 & 55 \\
Fosfomicina & 0 & 0 & 0 & 0 & 20 & 100 \\
Estreptomicina & 6 & 30 & 5 & 25 & 9 & 45 \\
\hline
\end{tabular}

vas potencialmente patógenas, ocasionando enterocolitis y muerte (Matsuura et al., 2010). Sin embargo, la presencia de aislados de Salmonella resistentes podría deberse a mecanismos propios de la bacteria, y no debido a su uso en la producción de cuyes. Existen estudios que han demostrado la importancia de mecanismos propios de Salmonella como bombas de eflujo en la resistencia a eritromicina (Braoudaki y Hilton, 2005).

En este estudio el 25\% (5/20) de aislados fueron resistentes a penicilina y ninguno a amoxicilina con ácido clavulánico. Si bien Matsuura et al. (2010) señalan que está contraindicado el uso de betalactámicos en cuyes por su toxicidad, de manera similar a los macrólidos, se consideró importante evaluar la resistencia a betalactámicos por la posible presencia de betalactamasas, enzimas que degradan betalactámicos y se encuentran involucradas en resistencia y fracasos terapeúticos (Shaikh et al., 2015). La presencia de aislados resistentes a penicilina y la ausencia de ellos a amoxicilina con ácido clavulánico podría deberse a que este último es un inhibidor de betalactamasas, permitien- do la acción antimicrobiana de la amoxicilina (Navarro et al., 2011).

El 40 y $30 \%$ de aislados fueron resistentes a nitrofurantoína y estreptomicina, respectivamente. Estas frecuencias fueron mayores a los hallados por Matsuura et al. (2010), quienes no encontraron aislados resistentes a estreptomicina y solo el $15 \%$ (6/40) de resistencia a otro nitrofurano, la furazolidona. Según Chauca (1997), los nitrofuranos y la estreptomicina son drogas de elección para el tratamiento de salmonelosis en cuyes. La aparición de cepas resistentes podría explicarse por el uso rutinario y no controlado para el control de la enfermedad en la producción de cuyes. Por otro lado, los resultados obtenidos para fosfomicina y sulfatrimetoprim son similares a los obtenidos por Matsuura et al. (2010).

Finalmente, no hubo aislados resistentes a ciprofloxacina, una quinolona de segunda generación, pero se detectó $10 \%(2 / 20)$ de resistencia y 45\% (9/20) de sensibilidad intermedia para enrofloxacina, una quinolona de tercera generación. En el Perú, es común 
utilizar enrofloxacina como tratamiento de salmonelosis en cuyes (Matsuura et al., 2010), por lo que su uso rutinario podría conducir a la aparición de aislados resistentes.

\section{Conclusiones}

- Todos los aislados de Salmonella (20/ 20) fueron identificados como Salmonella Typhimurium mediante una técnica de PCR múltiple, debido a la amplificación de los genes inv $\mathrm{A}$ y fliC, de 284 y $559 \mathrm{pb}$, respectivamente.

- La técnica BOX PCR identificó un patrón genético similar y de alta homogeneidad en todos los aislados de Salmonella Typhimurium.

- Se detectaron cepas de Salmonella Typhimurium MDR aisladas de cuyes con fenotipos resistentes a eritromicina, penicilina, nitrofurantoína, estreptomicina o enrofloxacina.

\section{Agradecimientos}

Los autores expresan su agradecimiento al Programa Nacional de Innovación para la Competitividad y Productividad - Innóvate Perú, fuente financiadora del Proyecto «Desarrollo de una vacuna para el control y prevención de la salmonelosis en la producción de cuyes», Contrato N ${ }^{\circ}$ 362-PNICP-PIAP2014, y a los propietarios de los centros de crianza de cuyes por brindar las facilidades para realizar el estudio.

\section{Literatura Citada}

1. Braoudaki M, Hilton AC. 2005 . Mechanisms of resistance in Salmonella enterica adapted to erythromycin, benzalkonium chloride and triclosan. Int J Antimicrob Agents 25: 31-37. doi: 10.1016/j.jjantimicag.2004.07.016

2. Casart Y, Falconí M. 2016. Tipificación molecular de Salmonella aislada de cuyes (Cavia porcellus) de
Loja, Ecuador. Rev Científ Ecuatoriana 3: 38-42.

3. Chauca L. 1997. Producción de cuyes (Cavia porcellus). Roma: Organización de las Naciones Unidas para la Agricultura y la Alimentación - FAO. 78 p.

4. [CLSI] Clinical and Laboratory Standards Institute. 2009. Performance standards for antimicrobial disk susceptibility M2-A10. $10^{\text {th }}$ ed. Pennsylvania, USA: CLSI. $172 \mathrm{p}$.

5. Fardsanei F, Nikkhahi F, Bakhshi B, Zahraei T, Asfari I, Soltan MM. 2016. Molecular characterization of Salmonella enterica serotype Enteritidis isolates from food and human samples by serotyping, antimicrobial resistance, plasmid profiling, (GTG) $)_{5}$ PCR and ERIC-PCR. New Microbe New Infect 14: 24-30. doi: 10.1016/j.nmni.2016.07.016

6. Guibourdenche M, Roggentin P, Mikoletit M, Fields PI, Bockemuhl J, Grimont PAD, Weill FX. 2010. Supplement 2003-2007 (No. 47) to the White-Kauffmann-Le Minor scheme. Res Microbiol 161: 26-29.

7. Jamshidi A, Kalidari G, Hedayati M. 2010. Isolation and identification of Salmonella Enteritidis and Salmonella Typhimurium from the eggs of retail stores in Mashhad, Iran using conventional culture method and multiplex PCR assay. J Food Safety 30: 558-568. doi: 10.1111/j.1745-4565.2010.00225.x

8. Learn-Han L, Yoke-Kqueen C, Salleh NA, Sukardi ES, Jiun-Horng ES, Chari-Hoon EK, Radu ES. 2008. Analysis of Salmonella Agona and Salmonella Weltevreden in Malaysia by PCR fingerprinting and antibiotic resistance profiling. Antonie van Leeuwenhoek 94: 377-387. doi: 10.1007/ s10482-008-9254-y

9. Lim H, Lee, KH, Hong CH, Bahk GJ, Choi WS. 2005. Comparison of four molecular typing methods for the differentiation of Salmonella spp. Int J Food Microbiol 105: 411-418. doi: 10.1016/j.ijfoodmicro.2005.03.019 
10. Lupiski JR, Weinstock GM. 1992. Short, interspersed repetitive DNA sequences in prokaryotic genomes. J Bacteriol 174: 4525-4529.

11. Matsuura A, Morales S, Calle S, Ara M. 2010. Antimicrobial in vitro susceptibility of Salmonella enterica isolated from guinea pigs of familiarcommercial breeding systems in the province of Carhuaz, Ancash. Rev Inv Vet Peru 21: 93-99. doi: 10.15381/ rivep.v21i1.355

12. Navarro F, Calvo J, Cantón R, Fernández-Cuenca F, Mirelis B. 2011. Detección fenotípica de mecanismos de resistencia en gramnegativos. Enferm Infecc Microbiol Clin 29: 524534. doi: 10.1016/j.eimc.2011.03.011

13. Pivnick SH, Stuart F, Walcroft M. 1966. Establishment of a Salmonellafree guinea pig colony. Can J Comp Med Vet Sci 30: 279-281.

14. Prasertsee T, Khantaprab N, Yamsakul $P$, Santiyanont $P$, Chokesajjawatee N, Patchanee P. 2016. Repetitive sequence-based PCR fingerprinting and the relationship of antimicrobial-resistance characteristics and corresponding genes among Salmonella strains from pig production. Asian Pac J Trop Dis 6: 390-395. doi: 10.1016/S2222-1808(15)61054-4

15. Rampadarath S, Puchooa, Bal S. 2015. Repetitive element palindromic PCR (rep-PCR) as a genetic tool to study interspecific diversity in Euphorbiaceae family. Electronic J Biotechnol 18: 412417. doi: 10.1016/j.ejbt.2015.09.003

16. Richardson VCG 2000. Diseases of domestic guinea pigs. $2^{\text {nd }}$ ed. USA: Blackwell Science. $144 \mathrm{p}$.

17. Sabat AJ, Budimir A, Nashev D, SáLeão $R$, van Dijl JM, Laurent F, Grundmann H, et al. 2013. Overview of molecular typing methods for outbreak detection and epidemiological surveillance. Euro Surveill 18(4): 20380.

18. Singh BR, Alam J, Hansda D. 2005. Alopecia induced by salmonellosis in guinea pigs. Vet Rec 156: 516-518.

19. Shaikh S, Fatima J, Shakil S, Rizvi S, Kamal, MA. 2015. Antibiotic resistance and extended spectrum beta-lactamases: types, epidemiology and treatment. Saudi J Biol Sci 22: 90-101. doi: 10.1016/ j.sjbs.2014.08.002

20. Su LH, Chiu CH, Chu C, Oи J. 2004. Antimicrobial resistance in nontyphoid Salmonella serotypes: a global challenge. Clin Infect Dis 39: 546-551. doi: $10.1086 / 422726$

21. Thermo Fisher Scientific. 2014. Thermo Scientific GeneJET Genomic DNA Purification Kit. User guide. [Internet]. Avalable in: https:// tools.thermofisher.com/content/sfs/ manuals/MAN0012663_GeneJET_Genomic_DNA_Purification_Kit_UG.pdf

22. Threfall EJ. 2002. Antimicrobial drug resistance in Salmonella: problems and perspectives in food- and water-borne infections. FEMS Microbiol Rev 26:141148. doi: 10.1111/j.1574-6976.2002.tb00606.x

23. Tunung R, Chai LC, Usha M, Lee HY, Fatimah AB, Farinazleen MG, Son $R$. 2007. Characterization of Salmonella enterica isolated from street food and clinical samples in Malaysia. ASEAN Food J 14: 161-173.

24. Versalovic J, Schneider M, de Bruijn FJ, Lupski JR. 1994. Genomic fingerprinting of bacteria using the repetitive sequence-based polymerase chain reaction. Methods Mol Cell Biol 5: 25-40.

25. Versalovic, J, Koeuth, T, Lupski, J. 1991. Distribution of repetitive DNA sequence in eubacteria and application to fingerprinting of bacterial genome. Nucleic Acid Res 19: 6823-6831. 